\title{
Lecithin Appearance and Apparent Biologic Half-Life in Term Newborn Rabbit Lung
}

\author{
ALAN JOBE, ${ }^{(32)}$ ELSA KIRKPATRICK, AND LOUIS GLUCK \\ Division of Perinatal Medicine, Department of Pediatrics, School of Medicine, University of California, San \\ Diego, La Jolla, California, USA
}

\begin{abstract}
Summary
The lung lecithin of term newborn rabbits was labeled by injecting the lecithin precursors palmitic acid and choline into the pregnant doe shortly before delivery of the newborn rabbits by cesarean section. The newborn lungs were lavaged to yield an alveolar wash lecithin sample and the tissue was homogenized and fractionated into lamellar body and microsomal fractions by differential and density gradient centrifugation. Lecithin was isolated from the lung parenchyma, microsomes, lamellar bodies, and alveolar wash by two-dimensional thin layer chromatography, and the specific activity of the lecithin in each fraction was determined. Curves are presented showing the time of appearance of the radioactive lecithin in each lecithin fraction. The apparent biological half-life of lecithin in each fraction was measured.

The specific activity of lecithin was high in microsomal fractions soon after palmitic acid or choline administration. The lamellar body fraction was free of radioactive lecithin for $3 \mathrm{hr}$, and maximal specific activity of lamellar body lecithin was reached only after $20 \mathrm{hr}$. The appearance of radioactive alveolar lecithin followed a curve very similar to that of the lecithin in the lamellar body fraction.

The apparent half-life of lung parenchymal lecithin from newborn lung labeled with palmitic acid was $57 \mathrm{hr}$, whereas the apparent half-life of alveolar lecithin was $136 \mathrm{hr}$. The lecithin in lung and alveolar wash labeled with choline had a longer halflife than did lecithin labeled with palmitic acid. Measurements of lecithin appearance and apparent half-life are compared to similar measurements in adult rabbits.
\end{abstract}

\section{Speculation}

The striking characteristics of newborn lung lecithin are the 3hr lag before the appearance in the alveolus of de novo synthesized lecithin, the prolonged time $(20 \mathrm{hr})$ before maximal specific activity of alveolar lecithin is achieved, and the very long apparent half-life of alveolar lecithin. If these measurements are applicable to other term and premature mammals, they must rely entirely on lecithin stored in anticipation of birth to maintain alveolar stability at birth. The long lag before significant lecithin synthesized de novo can reach the alveolar space precludes synthesis contributing to alveolar stability until many hours after birth. The recovery from the respiratory distress syndrome may not depend on maturation of the ability to synthesize lecithin; rather, the prolonged recovery phase may reflect the long times required for appreciable quantities of $d e$ novo synthesized lecithin to reach the alveolar space. However, once alveolar stability is achieved, short interruptions of lecithin synthesis, by reversible acidosis, for example, should not cause respiratory distress mediated by lecithin deficiency.

The times required for lecithin synthesis and appearance in the alveolar space and the biological half-life of alveolar surfac- tant lecithin are measurements essential to an understanding of surfactant physiology. These measurements have been made in the adult rat using several different radioactive lecithin precursors to pulse label lecithin $(3,10,11,21,27-29)$ and in adult mice using autoradiographic techniques $(8)$. Recently we reported the time of appearance of pulse labeled lecithin in the alveolar space and the biological half-life values for alveolar and lung lecithin in adult rabbits (18).

There are no reported studies of the kinetics of the appearance or decay of lecithin in newborn animals. Birth, and especially premature birth, ordinarily is the only event in the life of a mammal when the surfactant system of the lung is stressed. The cellular kinetics of lung lecithin may be very different in the newborn than the adult, reflecting either basic metabolic differences in the newborn animal or the stressful event of birth.

Considerably more information concerning the intracellular synthesis and storage of lecithin may be obtained from isolation of microsomal and lamellar body fractions of lung (18). The microsomes are known to be the principal site of synthesis of lecithin while the lamellar bodies appear to be the storage and secretory organelles for surfactant (20). The kinetics of the appearance of lecithin and its stability in the term newborn rabbit lung are presented here.

\section{MATERIALS AND METHODS}

\section{ANIMALS}

Pregnant rabbits of known gestation were killed at 30.2 days of a 31-day gestation. Each pregnant doe was given $600 \mathrm{mg}$ pentobarbital rapidly iv and the newborn rabbits were delivered by cesarean section within $2 \mathrm{~min}$. The newborn rabbits did not have respiratory distress and were considered to be at term. The newborns were placed in a warm, humid incubator until needed. They weighed from 38-75 g each, the weight varying with litter size. Newborn animals kept for more than $6 \mathrm{hr}$ were fed by gavage with $1 \mathrm{ml}$ SMA 20 calorie infant formula every $4 \mathrm{hr}$. Some newborns were maintained for 5 days with no weight loss, remaining very vigorous. There was no mortality.

\section{ISOTOPES}

Palmitic acid $\left(9,10-{ }^{3} \mathrm{H}, 470 \mathrm{Ci} / \mathrm{mmol} ; 16-{ }^{14} \mathrm{C}, 53 \mathrm{mCi} / \mathrm{mol}\right.$; and $1{ }^{14} \mathrm{C}, 52 \mathrm{mCi} / \mathrm{mmol}$ ) and choline chloride (methyl ${ }^{3} \mathrm{H}, 4.2$ $\mathrm{Ci} / \mathrm{mmole}$ ) were purchased from New England Nuclear, Boston, MA. The choline isotope was diluted in physiologic saline for use. The palmitic acid was converted to the sodium salt by boiling for $5 \mathrm{~min}$ in alkaline saline followed by dilution with an equal volume of $6 \%$ bovine serum albumin (Armour) in saline. The resulting solution was filtered through a Millipore filter after adjustment to $\mathrm{pH} 7.4$. The final solutions $(50 \mu \mathrm{Ci} / \mathrm{ml}$ $\left[{ }^{14} \mathrm{C}\right]$ palmitic acid and $200 \mu \mathrm{Ci} / \mathrm{ml}\left[{ }^{3} \mathrm{H}\right]$ palmitic acid) were stored at $-20^{\circ}$ until ready for use. 


\section{ISOLATION OF FRACTIONS}

The newborn animals were anesthesized with ip pentobarbital and were exanguinated by severing the abdominal aorta. The chest was opened and the trachea cannulated. An alveolar wash fraction was obtained with five $2-\mathrm{ml}$ saline endobronchial lavagings (15). The washes were pooled and extracted without centrifugation. Although alveolar cells (principally macrophages) contain lecithin, the quantity, relative to the total alveolar wash lecithin, is small (10). The lung was removed from the animal, weighed, and divided; $0.1-0.15 \mathrm{~g}$ was minced, homogenized, and extracted to yield a lung parenchymal lipid extract, and about $1.5 \mathrm{~g}$ were minced and processed for lamellar body and microsomal fractions. The lung of a $50 \mathrm{-g}$ newborn rabbit weighed about $1 \mathrm{~g}$ before alveolar wash and about $1.7 \mathrm{~g}$ after the wash since saline was retained by the tissue. The bleeding of the animal followed by the alveolar wash removed essentially all of the blood from the newborn lungs.

Subcellular fractions were isolated by the procedure of Gil and Reiss (13), modified for newborn lung. The lung was first minced with scissors. The tissue was homogenized in $5 \mathrm{ml} 0.32$ $\mathrm{M}$ sucrose-Tris- $\mathrm{NaCl}$ buffer $(0.32 \mathrm{M}$ sucrose in $0.01 \mathrm{M}$ Tris$\mathrm{HCl}, 0.15 \mathrm{M} \mathrm{NaCl}, 0.001 \mathrm{M} \mathrm{CaCl}_{2}, 0.001 \mathrm{M} \mathrm{MgSO}_{4}$, and $0.0001 \mathrm{M}$ EDTA) at $\mathrm{pH} 7.4$ with 3 strokes of a motor-driven Teflon pestle homogenizer at $250 \mathrm{rpm}$ (clearance $0.1-0.15 \mathrm{~mm}$, Arthur Thomas Co.). This crude homogenate was centrifuged at $1,000 \times g$ for $5 \mathrm{~min}$, and the supernatant was filtered through one layer of Kodak lens paper. The large pellet was discarded, and the supernatant was centrifuged at $7,700 \times g$ for $20 \mathrm{~min}$ to obtain a mitochondrial-lamellar body pellet and a supernatant containing the microsomes. The lamellar body-mitochondrial pellet was resuspended in $2 \mathrm{ml} 0.32 \mathrm{M}$ sucrose Tris- $\mathrm{NaCl}$ buffer and layered on a sucrose discontinuous gradient containing $9 \mathrm{ml}$ $0.55 \mathrm{M}$ sucrose in Tris- $\mathrm{NaCl}$ buffer and $5 \mathrm{ml} 0.45 \mathrm{M}$ sucrose in Tris- $\mathrm{NaCl}$ buffer. Sucrose concentrations were verified with a refractometer. The discontinuous gradients were centrifuged in a SW 27.1 Spinco rotor at $25,000 \mathrm{rpm}$ for $3 \mathrm{hr}$. The band at the interface between $0.45 \mathrm{M}$ sucrose and $0.55 \mathrm{M}$ sucrose containing lamellar bodies was aspirated and the lipids extracted. The pellet containing particulate material with a density greater than 0.55 $\mathrm{M}$ sucrose was the crude mitochondrial fraction.

The lamellar body fraction isolated between $0.45 \mathrm{M}$ sucrose and $0.55 \mathrm{M}$ sucrose on the step gradient behaved as a stable particulate fraction with an isopycnic density of $1.07 \mathrm{~g} / \mathrm{ml}$ at $20^{\circ}$ when run on a continuous sucrose gradient (13). This fraction was rich in phospholipid content but with little protein (Table 1). Approximately $2-5 \%$ of the total lung lecithin was recovered in the lamellar body fraction of newborn rabbit lung, but fewer lamellar bodies were isolated if the newborns were permitted to breathe air for a period of time.

Table 1. Protein and phospholipid content of fractions of newborn rabbit lung ${ }^{1}$

\begin{tabular}{|c|c|c|c|c|c|}
\hline Fraction & $\begin{array}{c}\mathrm{mg} \\
\text { protein }\end{array}$ & $\begin{array}{c}\mu \text { mol } \\
\text { phos- } \\
\text { pholipid }\end{array}$ & $\begin{array}{c}\mu \mathrm{mol} \\
\text { phos- } \\
\text { pholipid/ } \\
\text { mg } \\
\text { protein }\end{array}$ & $\begin{array}{c}\mu \mathrm{mol} \\
\text { lecithin }\end{array}$ & $\begin{array}{c}\mu \mathrm{mol} \\
\text { lecithin/ } \\
\mathrm{mg} \\
\text { protein }\end{array}$ \\
\hline Initial homogenate & 82 & 20.5 & 0.25 & 7.1 & 0.087 \\
\hline $\begin{array}{l}1,000 \times g \text { super- } \\
\text { natant }\end{array}$ & 45.5 & 6.9 & 0.15 & 3.3 & 0.073 \\
\hline Microsomes & 1 & 0.49 & 0.45 & 0.16 & 0.146 \\
\hline Lamellar bodies & 0.06 & 0.66 & 11 & 0.38 & 6.3 \\
\hline $\begin{array}{l}\text { Crude mitochon- } \\
\text { drial pellet }\end{array}$ & 1.9 & 1.3 & 0.68 & 0.61 & 0.32 \\
\hline $\begin{array}{l}100,000 \times g \text { super- } \\
\text { natant }\end{array}$ & 28.7 & 0.77 & 0.03 & 0.40 & 0.014 \\
\hline
\end{tabular}

' Six newborn rabbits were killed immediately after delivery by cesarean section. The average lung weight was $1.37 \mathrm{~g}$. Lungs were fractionated as described in Materials and Methods.
Microsomes were isolated from the $7,700 \times g$ supernatant by layering the supernatnat over $5 \mathrm{ml}$ of $0.8 \mathrm{M}$ sucrose Tris- $\mathrm{NaCl}$ buffer. These gradients were spun at $100,000 \times g$ for $3 \mathrm{hr}$ and the pellets were extracted to give microsomal lipid extracts. The $0.8 \mathrm{M}$ sucrose removed small light particulate matter with a high lipid content that contaminated the microsome fraction.

The lamellar body fraction was checked for mitochondrial and cell membrane contamination with marker enzymes $(17,23)$. Mitochondrial succinate-cytochrome $c$ reductase and microsomal rotenone-insensitive NADPH-cytochrome $c$ reductase were assayed according to the method of Sottocasa et al. (26); membrane 5 -nucleotidase was assayed by the method of Gentry and Olsson (12). The lamellar body fraction did not contain measurable amounts of rotenone-insensitive NADPH-cytochrome $c$ reductase, succinate-cytochrome $c$ reductase, or 5'nucleotidase. These enzymes were present in the other appropriate fractions.

\section{LIPID ANALYSIS}

All lipid extracts were obtained by the method of Bligh and Dyer (5). Large samples were concentrated with a rotary flash evaporator, while smaller samples were dried under a stream of nitrogen. All purification of lecithin was done in two dimensions on silica gel $\mathrm{H}$ using chloroform, methanol, acetic acid, water $(65: 25: 8: 4, \mathrm{v} / \mathrm{v})$ as the first dimension solvent system and tetrahydrofurane, methylal, methanol, $2 \mathrm{~N}$ ammonium hydroxide $(80: 57: 15.6: 8.4, \mathrm{v} / \mathrm{v})$ for the second dimension as described previously (7). Two-dimensional thin layer chromatography removed the significant amounts of phosphatidyl inositol that cochromatographed with lecithin. The lecithin was visualized after brief exposure in iodine vapor, and the spots were sprayed with water and scraped. The lecithin was eluted from the silica by filtration through a Teflon Millipore filter using, successively, methanol and chloroform-methanol $(2: 1)$. Recovery was greater than $95 \%$. The lecithin samples were divided, one aliquot for phosphate determination by the method of Bartlett (4) and the other for radioactive counting. An average lecithin spot contained 0.2 to $1 \mu \mathrm{M}$ lecithin; one-fifth was used for phosphate analysis and three-fifths to determine radioactivity. Representative maximal counts per min determined specifically for ${ }^{3} \mathrm{H}$ and ${ }^{14} \mathrm{C}$ in these lecithin samples were 2000 and $500 \mathrm{cpm}$, respectively. Radioactivity was measured using Aquasol scintillation fluid (New England Nuclear) and standards for calculating channel overlap for ${ }^{3} \mathrm{H}$ and ${ }^{14} \mathrm{C}$. The standards were $\left[{ }^{3} \mathrm{H}\right]-$ and $\left[{ }^{14} \mathrm{C}\right]$ lecithin.

The fatty acids esterified on lecithin were analyzed by gasliquid chromatography after conversion to the fatty acid methyl esters (14). A 15:1 splitter was used before the flame ionization detector to collect each fatty acid as it eluted from the gas-liquid chromatography column.

Degradation of the C-1 carbon of the free fatty acids of lecithin was carried out by refluxing the silver salts of the lecithin fatty acids in carbon tetrachloride in the presence of bromine, according to the method of Anker (1). The liberated $\mathrm{CO}_{2}$ was trapped in Oxisorb and the radioactivity determined using Oxiprep scintillation fluid (New England Nuclear).

\section{RESULTS}

\section{ISOTOPE INT́EGRITY}

Newborn rabbits rapidly clear palmitic acid from the blood. This was demonstrated by injecting $\left[{ }^{14} \mathrm{C}\right]$ palmitic acid iv through the external jugular vein and aspirating $0.1 \mathrm{ml}$ blood from the hearts of newborn rabbits at various times. At $1 \mathrm{~min} 20 \%$ of the isotope was found in the lipid extract of blood, but fewer than $5 \%$ of the counts represented free fatty acid. Very low levels of isotope remained in the lipid extract from blood by $10 \mathrm{~min}$.

The integrity of palmitic acid labeled on the carboxylic acid (C-1) carbon was checked, since the experiments continued as 
lone as 5 days. Newborn rabbits were given $5 \mu \mathrm{Ci}\left[{ }^{14} \mathrm{C}\right]$ palmitic acid $/ 10 \mathrm{~g}$ animal wt iv and lipid extracts of lung were obtained from $3 \mathrm{hr}$ to 4 days after injection. The lecithin was purified, and the $\mathrm{C}-1$ carbon of the fatty acid esters was released as $\mathrm{CO}_{2}$ (see Materials and Methods). Essentially all of the radioactivity was released as ${ }^{14} \mathrm{CO}_{2}$, and no differences were noted between 3$\mathrm{hr}$ and 4-day animals. Known isotopically labeled palmitic acid $\left(1-{ }^{14} \mathrm{C}\right.$ - and $16-{ }^{14} \mathrm{C}$-labeled) were used to verify the technique.

The fatty acids from the lung lecithin of these same animals were also methylated and separated by gas-liquid chromatography. Each fatty acid was collected from the splitter and the radioactivity was determined. The fatty acid ester composition from the lung lecithin of these same animals was very similar to that reported previously (25). Palmitic acid comprised $52 \%$ of the fatty acid esters on lecithin and contained more than $90 \%$ of the radioactivity. There were no differences between animals receiving isotope $3 \mathrm{hr}$ before death and those receiving isotope 4 days before death. Therefore, the radioactive palmitic acid injected remained intact isotopically for the time course of these experiments.

\section{ANIMAL MODEL}

Uniformity of the specific activity of lecithin in each newborn lung was measured after administration of isotope iv to a pregnant doe. Eight fetuses with weights from 55-75 g were delivered by cesarean section $10 \mathrm{~min}$ after the mother was injected with $200 \mu \mathrm{Ci}\left[{ }^{14} \mathrm{C}\right]$ palmitic acid. The newborns were killed at $1 \mathrm{~h}$ of age, and the specific activity of the lecithin from the lung of each newborn was $1.2 \pm 0.1 \times 10^{4} \mathrm{cpm}\left[{ }^{14} \mathrm{C}\right]$ palmitic acid in lecithin per $\mu \mathrm{mol}$ lecithin phosphate. Approximately $0.01 \%$ of the palmitic acid given to the mother appeared in the Iung lecithin of each newborn, the lecithin containing consistently $50 \%$ of the counts in the lipid extract. In contrast, approximately $0.04 \%$ of the isotope appeared in liver lecithin. In a similar experiment approximately $0.1 \%$ of the $\left[{ }^{3} \mathrm{H}\right]$ choline isotope injected into the mother appeared in the lung lecithin of each newborn. These values represented an actual incorporation into a fetal lung of about $0.1 \mu \mathrm{g}\left[{ }^{14} \mathrm{C}\right]$ palmitic acid and $8.3 \mathrm{ng}$ $\left[{ }^{3} \mathrm{H}\right]$ choline. This preliminary experiment illustrates that the lung lecithin of each newborn of a litter can be labeled quite uniformly and sufficiently such that each newborn lung can be analyzed as an independent time point.

In all the experiments described below each pregnant rabbit was given two isotopes, either $\left[{ }^{3} \mathrm{H}\right]-$ and $\left[{ }^{14} \mathrm{C}\right]$ palmitic acid or $\left[{ }^{3} \mathrm{H}\right]$ choline and $\left[{ }^{14} \mathrm{C}\right]$ palmitic acid. One isotope was given 18 $24 \mathrm{hr}$ before delivery of the newborn rabbits as a tracer for that lecithin synthesized before birth. The second isotope was given $10 \mathrm{~min}$ before cesarean section delivery as a label for lecithin synthesized at birth

Figure 1 shows the data obtained from a litter of 10 animals receiving palmitic acid $18 \mathrm{hr}$ and choline $10 \mathrm{~min}$ before delivery by cesarean section. The palmitic acid incorporated into the lung parenchymal lecithin of fetal rabbits $18 \mathrm{hr}$ before delivery had a relatively constant specific activity over the 24-hr neonatal experimental period. Choline administered $10 \mathrm{~min}$ before delivery was incorporated into lecithin for several hours after birth. In contrast, when palmitic acid was injected into a pregnant doe 10 min before delivery, the maximal specific activity of lecithin was reached in newborn lung parenchyma within $1 \mathrm{hr}$ in an experiment similar to that in Figure 1 (data not shown).

The specific activity of alveolar lecithin labeled with palmitic acid given $18 \mathrm{hr}$ before delivery of the newborn rabbits changed little (Fig. 1). Although the amount of lecithin in the alveolar wash increased (Fig. 2), the specific activity of the alveolar lecithin was relatively constant for $24 \mathrm{hr}$, indicating that the $\left[{ }^{14} \mathrm{C}\right]$ palmitic acid-labeled lecithin to be released from the parenchyma and the $\left[{ }^{14} \mathrm{C}\right]$ palmitic acid-labeled lecithin already present in the alveolar space had similar specific activities. The lecithin labeled with choline at the time of birth began to appear at the alveolar space after a lag of $3 \mathrm{hr}$.

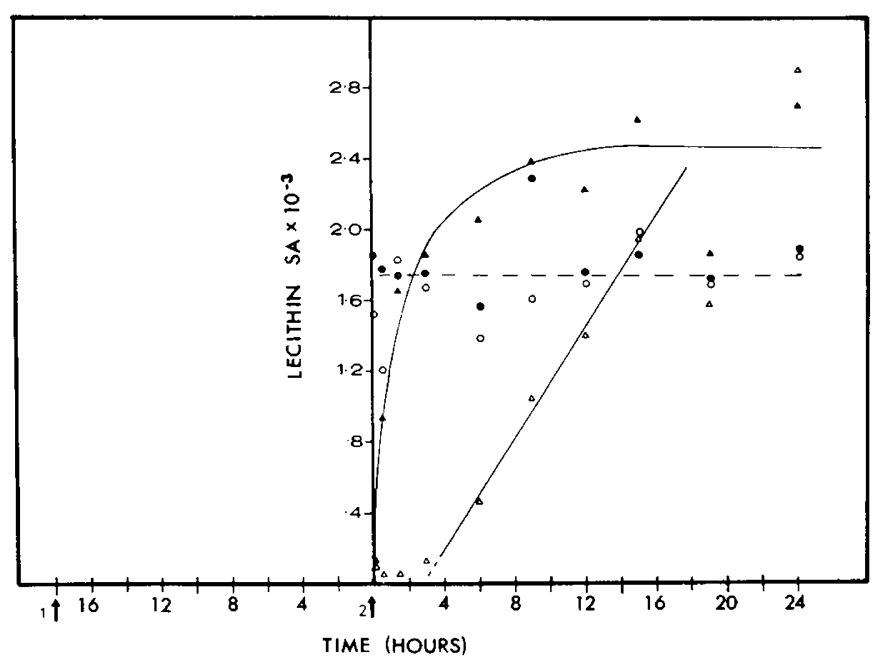

Fig. 1. Comparison of the specific activity of lecithin in lung parenchyma and alveolar wash; isotope given $18 \mathrm{hr}$ and $10 \mathrm{~min}$ before delivery. $\left[{ }^{14} \mathrm{C}\right]$ Palmitic acid, $200 \mu \mathrm{Ci}$, was given iv to a pregnant doe 18 $\mathrm{hr}$ before delivery by cesarean section of 10 newborn rabbits (arrow 1) and $250 \mu \mathrm{Ci}\left[{ }^{3} \mathrm{H}\right.$ ]choline was given similarly $10 \mathrm{~min}$ before delivery (arrow 2). The newborn rabbits were killed and the specific activity (SA) of the lecithin in alveolar wash and lung parenchyma was determined. $\mathrm{SA}=$ counts per min precursor in lecithin per $\mu$ mol lecithin phosphate. $\Delta$ : $\left[{ }^{3} \mathrm{H}\right]$ choline, lung parenchyma; $\triangle:\left[{ }^{3} \mathrm{H}\right]$ choline, alveolar wash; $-\left[{ }^{14} \mathrm{C}\right]$ palmitic acid, lung parenchyma; $\bigcirc:\left[{ }^{14} \mathrm{C}\right]$ palmitic acid, alveolar wash

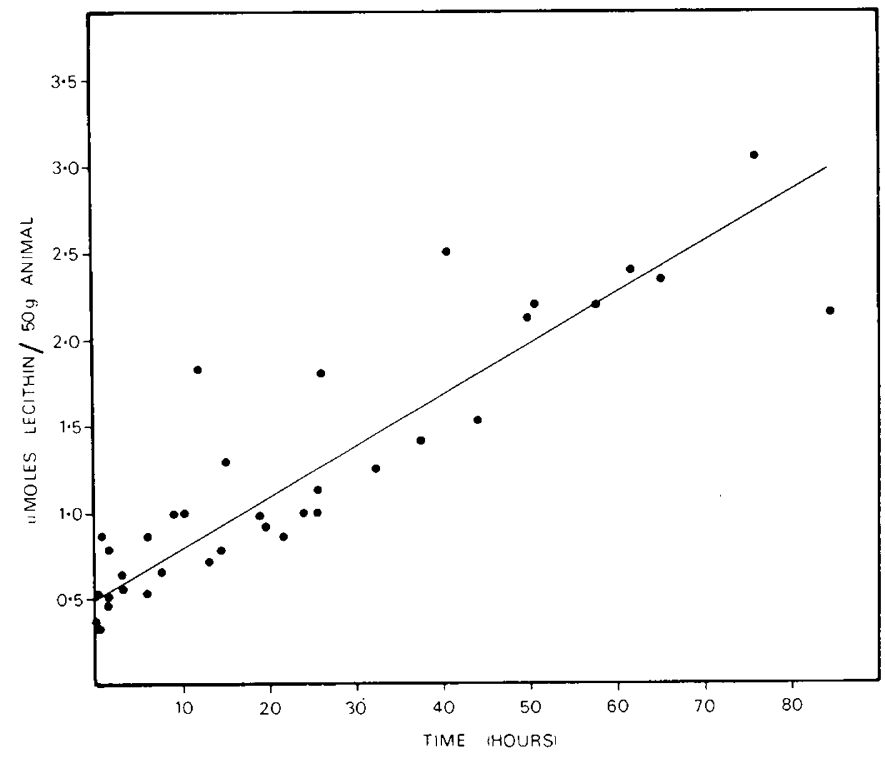

Fig. 2. Alveolar lecithin in newborn rabbits. Each point represents the micromoles of lecithin isolated from the alveolar wash of newborn rabbits at the time after birth indicated on the time axis. The data is normalized to an animal weight of $50 \mathrm{~g}$. The protein, DNA, or weight of lung may change over the period of an experiment. The only number that practically can be obtained for all animals in a litter at the same time is animal weight. Lung weight before alveolar wash correlates reasonably well with animal weight (lung weight/animal weight $=$ 0.018 ). The average weight of a newborn rabbit is about $50 \mathrm{~g}$, and this number is used to normalize to a standard animal size the amount of lecithin in the alveolar wash of each rabbit of a litter.

\section{LECITHIN APPEARANCE IN LUNG MICROSOMES, LAMELLAR BODIES, AND ALVEOLAR WASH}

The fractionation of lung into microsomes and lamellar bodies with subsequent determination of specific activity of lecithin permitted the analysis of the two lung fractions directly related 


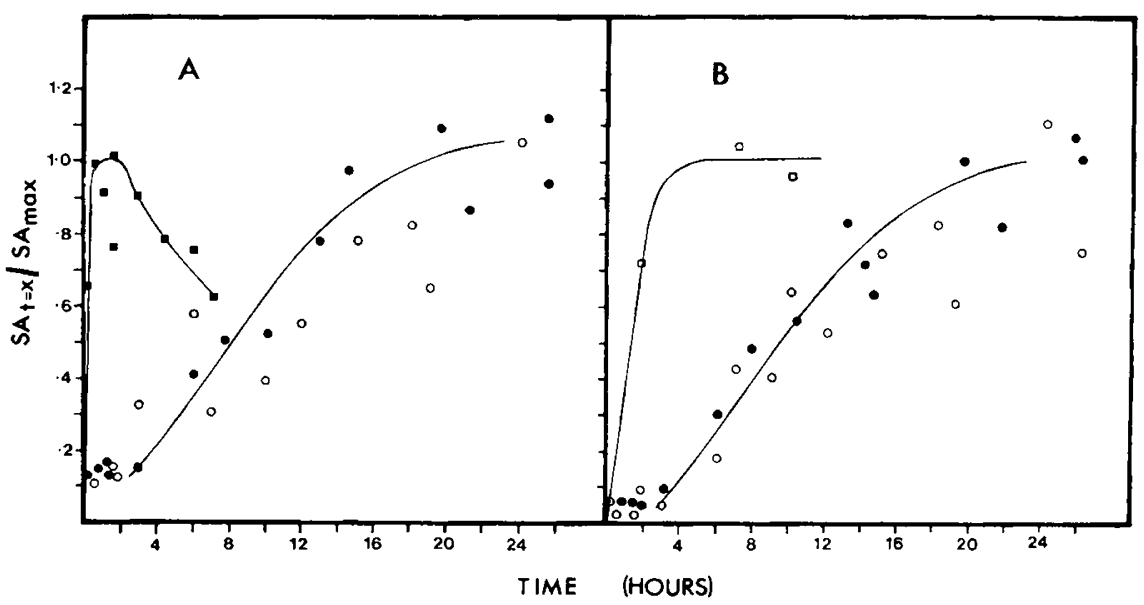

Fig. 3. Appearance of labeled lecithin in microsomal, lamellar body, and alveolar wash fractions. The data of several experiments were pooled. In each case either $\left[{ }^{14} \mathrm{C}\right]$ - or $\left[{ }^{3} \mathrm{H}\right]$ palmitic acid (solid symbols), or $\left[{ }^{3} \mathrm{H}\right]$ choline (open symbols) was given to the pregnant rabbit 10 min before delivery by cesarean section. The elapsed time is from the time of isotope administration. The newborn rabbits were killed at the times indicated. The lungs were fractionated and the specific activity for each fraction determined. A best estimate of maximal lecithin specific activity $\left(\mathrm{SA}_{\max }\right)$ achieved in each fraction was determined graphically and the specific activity at each time point $\left(\mathrm{SA}_{\mathrm{t}=\mathrm{x}}\right)$ was expressed as a ratio of the maximal specific activity $\left(\mathrm{SA}_{t=\mathrm{x}} / \mathrm{SA}_{\max }\right) . A: \boldsymbol{\square}$, palmitic acid in microsomal lecithin; $\bullet$, palmitic acid in lamellar body lecithin; $O$, choline in lamellar body lecithin. $B$ : $\square$, choline in microsomal lecithin; $\bullet$, palmitic acid in alveolar wash lecithin; $O$, choline in alveolar wash lecithin.

Table 2. Time (hours) required for specific activity of lecithin to approximate maximum in rabbit lung fractions

\begin{tabular}{lccccc}
\hline & \multicolumn{3}{c}{ Lecithin precursors } \\
\cline { 2 - 3 } \multicolumn{1}{c}{ Lung fraction } & \multicolumn{2}{c}{ Palmitic acid } & & \multicolumn{2}{c}{ Choline } \\
\cline { 2 - 3 } \cline { 5 - 6 } \cline { 5 - 6 } Newborn & Adult $^{1}$ & & Newborn & Adult $^{1}$ \\
Lung parenchyma & 1 & 0.5 & & 6 & 1 \\
Microsomes & $<0.5$ & $<0.05$ & & 1 & 0.25 \\
Lamellar bodies & 20 & 2 & & 20 & 2 \\
Alveolar wash & 20 & 6 & & 20 & 6 \\
\hline
\end{tabular}

1 Times determined previously for adult rabbits (18).

surfactant synthesis, storage and secretion. The curves of appearance of microsomal lecithin, lamellar body lecithin, and alveolar wash lecithin are presented in Figure 3. The time required for specific activity of lecithin to reach a maximum is presented in Table 2, and comparison values for adult rabbits are included (18). The specific activity of microsomal lecithin increased rapidly when palmitic acid was the precursor of lecithin and more slowly when choline was the precursor. The maximum specific activity in the microsomal fraction preceded that in the lung parenchyma ( 1 vs. $6 \mathrm{hr}$ when choline was the precursor), consistent with the function of microsomes as the principal site of lecithin synthesis.

Radioactive lecithin labeled with either choline or palmitic acid began to appear in lamellar bodies (Fig. $3 A$ ) only after a delay of $3 \mathrm{hr}$ from the time of injection of the precursor of lecithin. This was at least $2 \mathrm{hr}$ after maximal specific activity was achieved in the microsomal fractions (Table 2). The specific activity of lamellar body lecithin continued to increase for about $20 \mathrm{hr}$, indicating very prolonged accumulation of pulse-labeled lecithin. During the period of increasing specific activity in lamellar bodies, the specific activity of the microsomal fraction decreased by $50 \%$ (Fig. 4).

The curves for appearance of lecithin labeled with either choline or palmitic acid in the alveolar wash were very similar to the curves for the appearance of similarly labeled lecithin in the lamellar bodies (Fig. 1, Fig. 3B). The same 3 -hr delay from the time of isotope administration was evident, and maximal specific activity was not achieved for about $20 \mathrm{hr}$.

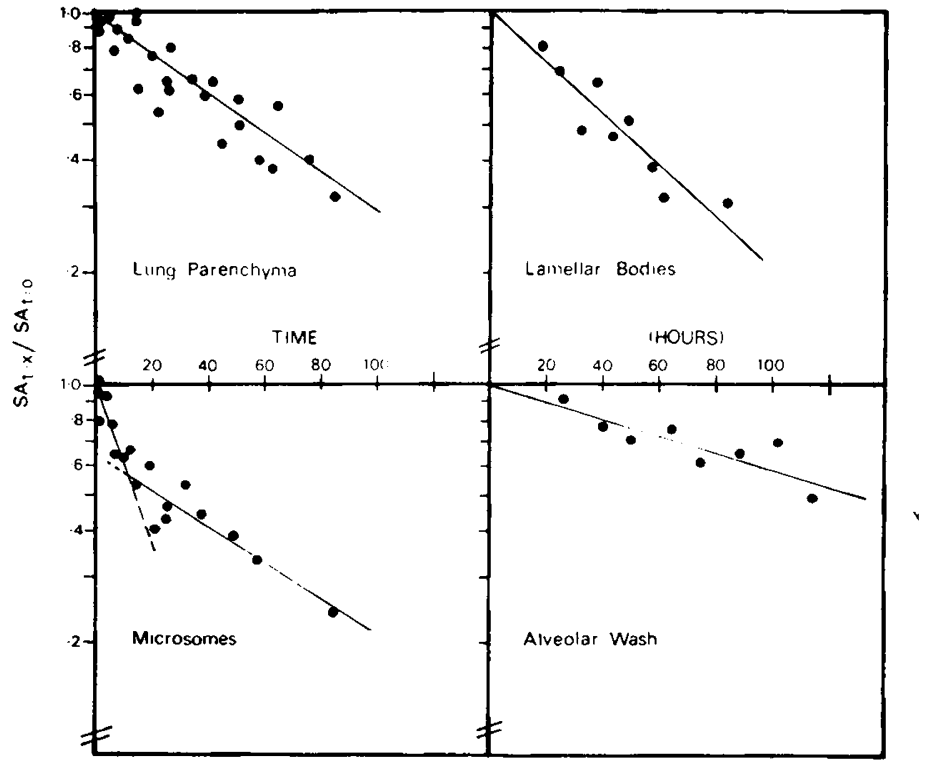

Fig. 4. Biologic half-life of newborn rabbit lung lecithin labeled with palmitic acid at birth. Newborn animais were killed at the times indicated after either $250 \mu \mathrm{Ci}$ of $\left[{ }^{14} \mathrm{C}\right]$ - or $2 \mathrm{mCi}$ of $\left[{ }^{3} \mathrm{H}\right]$ palmitic acid was given to pregnant does $10 \mathrm{~min}$ before delivery, and the lecithin specific activities (SA) in lung parenchyma, microsomes, lamellar bodies, and alveolar wash were determined. The SA data were linearized by a $\log _{10}$ transformation, and a least squares estimate of the regression equation was calculated. The SA at time $=0$, as determined from the exponential form of the regression equation, was defined as 1.0 and the experimental $S A$ values were normalized. The line determined from the regression equation and the normalized SA data expressed as $\mathbf{S A} t=\mathbf{x} / \mathbf{S A} t=0$ are presented for each lung fraction.

\section{LECITHIN ACCUMULATION IN NEWBORN LUNG}

Although the amount of lecithin in the lung parenchyma and alveolar wash of an adult animal was quite constant, newborn rabbits were shown to accumulate lecithin in the parenchyma and alveolar wash during late gestation and soon after birth (16). Figure 2 demonstrates that the amount of lecithin that 
could be isolated from the alveolar space of term newborn animals continued to accumulate linearly at a rate of $0.03 \mu \mathrm{mol}$ lecithin $/ \mathrm{hr} / 50 \mathrm{~g}$ animal wt for at least 3 days after delivery. Accumulation also was noted in the lung parenchyma. However, different litters had different rates of accumulation of parenchymal lecithin, varying from $0-0.13 \mu \mathrm{mol}$ lecithin $/ \mathrm{hr} / 50 \mathrm{~g}$ animal wt. There was no apparent reason for the interlitter variation. It was not possible to measure accurately how the quantity of lecithin in lamellar body or microsomal lung fractions might change from birth to several days of life.

\section{APPARENT BIOLOGIC HALF-LIFE $\left(\mathrm{t}_{1 / 2}\right)$ OF LECITHIN}

The half-life data is qualified to measure an apparent biologic half-life because several assumptions basic to half-life measurements cannot be fulfilled in experiments with newborn animals, as explained under Discussion. Figure 4 gives the apparent halflife data for lecithin in the four lung fractions when palmitic acid was given as a precursor of lecithin $10 \mathrm{~min}$ before delivery. Similar data are shown in Figure 5; however, the palmitic acid was given $22 \mathrm{hr}$ before delivery of the newborn rabbits. Table 3 summarizes the apparent $t_{1 / 2}$ values for the newborn lung and contrasts the results with the results from the adult rabbit lung (18). The decay curves for lecithin synthesized before and at birth were very similar. The one exception was the initial rapid disappearance from microsomes of lecithin synthesized at birth (Fig. 4). The rapid decay component of the curve probably represents lecithin moving out of microsomes toward the alveolar space. The slow component of the curve may represent more permanent structural lecithin in microsomal membranes. The same phenomenon was noted in adult rabbit microsomes (18)

\section{SUMMATION OF RADIOACTIVITY IN NEWBORN LUNGS}

An independent way to verify the prolonged apparent halflife of lecithin in newborn lung was by the summation of all the

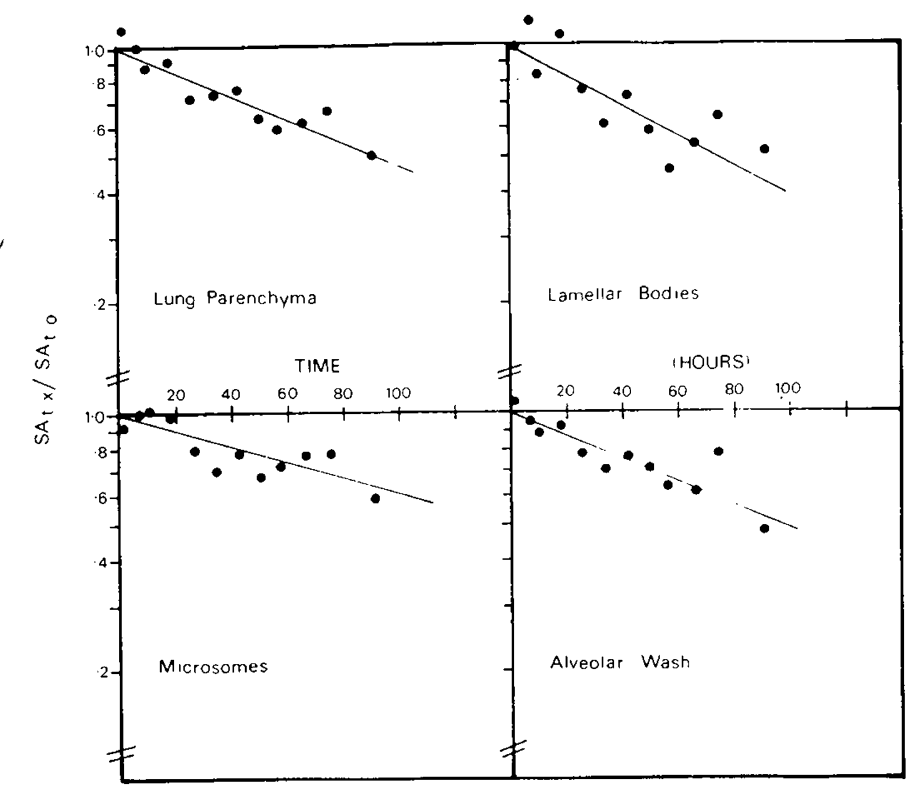

Fig. 5. Biologic half-life of newborn rabbit lung lecithin labeled with palmitic acid $22 \mathrm{hr}$ before delivery. The data is from the analysis of lecithin specific acitivty (SA) from the lungs of one litter of 12 newborn animals. The pregnant rabbit was given $250 \mu \mathrm{Ci}$ of $\left[{ }^{14} \mathrm{C}\right]$ palmitic acid 22 $\mathrm{hr}$ before delivery of the litter by cesarean section. The ordinate indicates time rabbits were killed after birth. The data points were normalized and the regression equations for the lines were determined as in Figure 4 . The specific activity of each initial experimental time point was: $1655 \mathrm{cpm} / \mu \mathrm{mol}$ lecithin for lung parenchyma; $1206 \mathrm{cpm} / \mu \mathrm{mol}$ lecithin for microsomes; $1778 \mathrm{cpm} / \mu \mathrm{mol}$ lecithin for lamellar bodies; and $1574 \mathrm{cpm} / \mu \mathrm{mol}$ lecithin for the alveolar wash.
Table 3. Apparent biologic half-life of lecithin in newborn lung and biologic half-life of lecithin in adult lung

\begin{tabular}{|c|c|c|c|c|}
\hline Lecithin precursor & $\begin{array}{c}\text { Lung } \\
\text { parenchyma }\end{array}$ & $\begin{array}{l}\text { Micro- } \\
\text { somes }\end{array}$ & $\begin{array}{c}\text { La- } \\
\text { mel- } \\
\text { lar } \\
\text { bodies }\end{array}$ & $\begin{array}{c}\text { Alveolar } \\
\text { wash }\end{array}$ \\
\hline \multicolumn{5}{|l|}{10 min before delivery } \\
\hline Palmitic acid & 57 & $15^{1}(58)^{2}$ & 45 & 136 \\
\hline Choline & $>100$ & & & \\
\hline \multicolumn{5}{|l|}{$18-24 \mathrm{hr}$ before delivery } \\
\hline Palmitic acid & 94 & 140 & 76 & 97 \\
\hline Choline & $>100$ & & & $>200$ \\
\hline \multicolumn{5}{|l|}{ Adult rabbits $^{3}$} \\
\hline Palmitic acid & $9(26)$ & $4(34)$ & 16 & 16 \\
\hline Choline & $13(59)$ & $4(77)$ & 33 & 35 \\
\hline
\end{tabular}

${ }^{1}$ Initial slope of decay curve.

${ }^{2}$ Half-life value determined for that part of the curve after the slope change (Fig. 4).

${ }^{3}$ Times determined previously for adult rabbits (18). The exponential decay data were transformed to a linearized form $\left(\log _{10}\right)$, and a least squares estimate of the slope was calculated. The $t_{1 / 2}$ was calculated from the slope and was rounded off to the nearest hour. The $t_{1 / 2}$ values given for decay of lecithin labeled with choline are minimal estimates.

Table 4. Total counts per min in lecithin labeled with palmitic acid in lung parenchyma plus alveolar wash per $50 \mathrm{~g}$ animal weight ${ }^{1}$

\begin{tabular}{cccc}
\hline \multicolumn{2}{c}{ Experiment 1} & \multicolumn{2}{c}{ Experiment 2 } \\
\cline { 3 - 4 } \cline { 3 - 4 } $\begin{array}{c}\text { Elapsed time, } \\
\text { hr }\end{array}$ & $\mathrm{cpm} \times 10^{4}$ & $\begin{array}{c}\text { Elapsed time, } \\
\text { hr }\end{array}$ & $\mathrm{cpm} \times 10^{4}$ \\
\hline 1.5 & 2.0 & 1.7 & 1.2 \\
7.75 & 2.3 & 7 & 1.0 \\
13 & 2.8 & 10 & 1.1 \\
19.5 & 2.4 & 18 & 0.9 \\
25.5 & 2.0 & 26 & 0.7 \\
32.5 & 2.9 & 34 & 1.0 \\
37.5 & 2.7 & 42 & 1.1 \\
44 & 2.0 & 50 & 0.8 \\
49.5 & 2.5 & 57 & 0.5 \\
& & 60 & 0.9 \\
& & 75 & 0.9 \\
& & 91 & 0.7 \\
\hline
\end{tabular}

${ }^{1}$ The isotope was given $10 \mathrm{~min}$ before delivery of the newborn rabbits.

radioactivity in the lung (defined here as lung parenchyma plus alveolar wash). If the total lecithin radioactivity in the lung remained relatively constant during the experimental period, very little lecithin was being degraded. There was, of course, no way to determine whether a labeled precursor was moving from one lecithin molecule to a similar lecithin molecule. The actual data for the total counts per min in $\left[{ }^{14} \mathrm{C}\right]$ palmitic acid labeled lecithin per $50 \mathrm{~g}$ animal wt is given in Table 4 . Very little of the $\left[{ }^{14} \mathrm{C}\right]$ palmitic acid incorporated initially into lung lecithin had disappeared by 3 days. The data was similar for choline, except lung counts increased for about $6 \mathrm{hr}$, indicating that radioactive choline continued to enter the newborn lung lecithin and that it was not a "clean" pulse label for lecithin in the newborn.

\section{DISCUSSION}

Early studies with autoradiographic techniques using adult mice showed that the type II cell was the principal source of surfactant lecithin $(2,6)$. These findings were supported by the studies of $\left[{ }^{3} \mathrm{H}\right]$ palmitic acid incorporation in mouse lung $1-10$ 
min after pulse labeling by Darrah and Hedley-Whyte (9). They demonstrated with biochemical techniques and autoradiography that the type II pneumocyte was the only cell type to incorporate the label significantly. Thus these studies showed that in vivo pulse label experiments of lung lecithin metabolism should reflect principally the lecithin metabolism of the type II pneumocyte.

Recently Chevalier and Collet (8) studied the synthesis and appearance of lung lecithin in the alveolar space using mouse lungs labeled in vivo with $\left[{ }^{3} \mathrm{H}\right]$ choline. With electron microscopic autoradiography, they found $\left[{ }^{3} \mathrm{H}\right]$ choline in the endoplasmic reticulum of the type II cell at $5 \mathrm{~min}$, and in lamellar bodies and the alveolar space by $2 \mathrm{hr}$. They formulated a sequence for the appearance in the lamellar body of lecithin labeled with choline. Labeled lecithin left the endoplasmic reticulum and migrated via the Golgi zone to a growing lamellar body which with time became a lamellar body. A small lamellated form, the small lamellar body was postulated as the vehicle for the transport of lecithin from the Golgi zone to the growing lamellar body (8). This anatomic description represents a framework for the interpretation of experiments designed to pulse-label lecithin with various precursors and to follow the radioactive lecithin through lung fractions to the alveolar space.

The appearance and half-life of labeled lecithin in lung parenchyma has been used as a measure of overall metabolism of lung lecithin $(3,10,11,21,27-29)$. Two different radioactive precursors of lecithin were used here to study lecithin metabolism; each precursor enters the lecithin molecule by different pathways. Choline is incorporated into lecithin primarily by the de novo synthetic pathway by way of cytidine diphosphocholine. Palmitic acid can enter preexisting lung lecithin by one of the deacylation-reacylation or transacylation mechanisms or by acylation of glycerol phosphate precursor pools utilized for de novo lecithin synthesis (20).

The specific activity of lecithin labeled with either palmitic acid or choline in microsomes increased rapidly after injection of isotope in both newborn and adult animals. The time required to reach maximal specific activity was slower in the newborn, although mechanisms are not known. The appearance of radioactive lecithin first in the microsomal fraction is consistent with the localization of the synthesis of lecithin primarily in the endoplasmic reticulum of the type II pneumocyte, as described by Chevalier and Collet (8).

There were significant differences in the appearance of radioactive lecithin in lamellar bodies of newborn and adult rabbits. Lamellar body lecithin in the adult rabbit became labeled almost immediately after administration of isotope (18), whereas lecithin labeled with palmitate or choline appeared in the lamellar body fraction of the newborn only after a 3-hr lag period (Fig. 3). Maximal specific activity of lecithin in lamellar bodies was achieved in about $2 \mathrm{hr}$ in the adult versus $20 \mathrm{hr}$ in the newborn. The 3-hr lag represents an obligate delay period when lecithin synthesized at birth is not available for alveolar stability. The biochemical explanation for the 3-hr delay in the appearance of radioactive lecithin in the lamellar body fraction may concern the growth process of lamellar bodies in newborn animals (8).

The alveolar wash of adult rabbits or rats had detectable radioactive lecithin within $0.5-1 \mathrm{hr}$ of injection of palmitic acid or choline, and maximal specific activity of lecithin was reached in $6 \mathrm{hr}(18,24)$. In contrast, the lag before radioactive lecithin appearance at the alveolar space in the newborn was $3 \mathrm{hr}$, and maximal specific activity of lecithin was not reached for about $20 \mathrm{hr}$. Radioactive lecithin appeared simultaneously in the alveolar space and in lamellar bodies in newborn rabbits indicating rapid release from the lamellar bodies to the alveolar space. Although the curves for appearance of lecithin in microsomes labeled with choline or palmitic acid were different, no differences were apparent in the curves for the appearance of labeled lecithin in lamellar bodies and the alveolar wash. As with adult rabbits, palmitic acid and choline could be used interchangeably as labels for lecithin in lamellar bodies and alveolar wash (18).
The biologic half-life of lecithin $\left(t_{1 / 2}\right)$ has been estimated in rat lung and in alveolar wash using pulse-labeling techniques. The $t_{1 / 2}$ varies, depending upon the precursor of lecithin chosen for study. When labeled palmitic acid, glucose, or glycerol was a precursor, rat lung and alveolar wash lecithin had $t_{1 / 2}$ values of about $15 \mathrm{hr}(3,11,27,28)$. Calculated half-life values for lecithin labeled with radioactive choline and phosphate were consideraly longer, being 45 and $75 \mathrm{hr}$, respectively $(3,28)$. The longer half-life values may represent reutilization of the component parts of the lecithin molecule. The total and disaturated lecithins in alveolar wash had similar initial exponential decay curves in rats; although several studies showed that the initial relatively rapid decay became more gradual after either 24 (29) or $48 \mathrm{hr}(3)$. These measurements in adult rats demonstrated that lecithin was being turned over at the alveolar space at rates far in excess of the turnover of lecithin either in rat brain (19) or liver microsomes (22).

The $t_{1 / 2}$ values for rabbit lung and alveolar wash were similar to those measured in the rat; however, in the rabbit the decay curves for total and disaturated lecithin in lung and alveoli were linear and superimposable (18).

These measurements of biological half-life in adult animals depend on assumptions that are not valid for newborn animals. A precursor of lecithin should act as a clean pulse label by being cleared from the blood and incorporated rapidly into lecithin. In the present study, the appearance of lecithin labeled with palmitic acid in microsomes and lung parenchyma was rapid. However, palmitic acid did not pulse label the lecithin of lamellar bodies or alveolar wash cleanly. The prolonged time required for the specific activity of lecithin to reach a maximum and begin to decay $(20 \mathrm{hr})$ actually represented the time the label was appearing in the lecithin of the lamellar body and alveolar wash fractions, clearly not a pulse label. The continued entrance of labeled lecithin into lamellar body and alveolar wash fractions tends to increase the measured biologic half-life. The same problem was encountered to a more limited extent in the half-life measurements for adult rabbit (18).

The continued entrance of lecithin precursors from other body pools (e.g., liver or blood) long after the initial pulse label would also artificially prolong a measured half-life. Very small amounts of isotope were transferred across the placenta to the fetal animals and the isotope should be rapidly assimilated and diluted in large body pools. Palmitic acid was demonstrated to be rapidly cleared from the newborn rabbit blood. This problem was discussed previously and was discounted as a major complication of the half-life measurements $(28,29)$.

Accurate half-life measurements also require an equilibrium condition for lecithin within each cellular fraction, i.e., the quantity of lecithin in each lung fraction should be constant over the time course of the experiment. The lecithin concentration was relatively unchanging in the lungs of adult animals (27), but newborn rabbits accumulated lecithin in the lung parenchyma and alveolar wash. Thus, straightforward measurements of biologic half-life were not possible in newborn animals. The accumulation of lecithin within any fraction of lung diluted the pulse label, making the measured or "apparent" $t_{1 / 2}$ appear shorter than it actually would be. For example, the apparent $t_{1 / 2}$ for lecithin in newborn lung parenchyma (Fig. 4) of $57 \mathrm{hr}$ could be corrected for accumulation, to yield a $t_{1 / 2}$ of greater than 6 days, indicating the magnitude of the error introduced by accumulation. Acknowledging the limitations of the apparent $t_{1 / 2}$ values determined in the newborn rabbits, the numbers do indicate the relative stability of lecithin.

The apparent half-life of lecithin was greater in the newborn lung fractions and alveolar wash than in the adult rabbit. The data apparently represented single component decay curves (with the exception of the microsomal curve, Fig. 4); however, the half-life values were sufficiently long that large changes in specific activity of lecithin were not noted. Although longer experiments could be performed, the data would be very difficult to interpret because of the rapid growth and development of 
these newborn animals. Of note was the apparent half-life of alveolar lecithin ( $>4$ days), indicating that any lecithin delivered to the alveolar space would remain to influence alveolar stability. The prolonged half-life, coupled with continued lecithin synthesis, possibly accounted for the accumulation of lecithin in the. lung tissue and alveolar space. Lecithin synthesized 18-24 hr before birth had somewhat larger half-life values than did the lecithin synthesized at birth.

The mechanisms responsible for turnover of alveolar lecithin in the adult animal are not known. Proposed hypotheses are digestion of lecithin by alveolar macrophage, broncheal and tracheal ciliary action moving surfactant to the glottis to be swallowed, phospholipase degradation, and lymphatic absorption (21). The prolonged half-life of phospholipid in the newborn may reflect a general property of immature tissue. Recently, Rosenthal and Geyer (24) showed that human fetal fibroblasts in tissue culture did not turn over phospholipid acyl groups, whereas cell lines derived from adult fibroblasts did.

In the newborn the prolonged time required for lecithin to appear at the alveolar space contrasts sharply with the rapid release of stored lecithin at birth (16) and the progressive accumulation of lecithin at the alveolar space. The term newborn apparently has adequate surfactant stores such that he does not require de novo synthesized lecithin for alveolar stability at birth. The premature animal with little surfactant phospholipid stored in anticipation of birth is unable to rely on stored lecithin; survival may depend on ventilatory support until the delayed delivery to the alveolus of de novo synthesized lecithin can begin.

The biologic half-life values for adult rats and rabbits have been found to be similar $(3,10,11,18,21,27-29)$. Possibly these results with newborn rabbits may be generalized to other newborn animals. The prolonged time required for lecithin synthesized at birth to appear at the alveolar space is consistent with the prolonged course of the RDS in the newborn human. The prolonged half-life of alveolar lecithin in newborns argues against an increased destruction of lecithin contributing to RDS.

\section{CONCLUSION}

The lung lecithin of term newborn rabbits was pulse labeled with radioactive choline and palmitic acid. The appearance of the labeled lecithin in the four lung fractions, parenchyma, microsomes, lamellar bodies, and alveolar wash, was measured. The disappearance or apparent biologic half-life of the labeled lecithin in each lung fraction also was determined. Lecithin appears more slowly at the alveolus of the newborn than the adult rabbit and has a prolonged biologic half-life.

\section{REFERENCES AND NOTES}

1. Anker, H. S.: On the mechanism of fatty acid synthesis in vivo. J. Biol. Chem., 194: 177 (1952).

2. Askin, F. B., and Kuhn, C.: The cellular origin of pulmonary surfactant. Lab Invest., 25: $260(1971)$

3. Balint, J. A., Beeler, D. A., Kyriakides, E. C., and Treble, D. H.: Studies on the biosynthesis of pulmonary surfactant lecithin. Chest, 67: (Suppl.) 21S (1975).

4. Bartlett, G. R.: Phosphorus assay in column chromatography. J. Biol. Chem., 234: 466 (1959).

5. Bligh, E. G., and Dyer, W. J.: A rapid method of total lipid extraction and purification. Can. J. Biochem. Physiol., 37: 911 (1959).
6. Buckingham, S., Heinemann, H. O., Sommers, S. C., and McNary, W. F Phospholipid synthesis in the large pulmonary alveolar cell. Amer. J. Pathol., 48: 1027 (1966)

7. Bustos, R., Kulovich, M. V., Gluck, L., Gabbe, S. G., Evertson, L., Vargas, C., and Lowenberg, E.: Significance of phosphatidylglycerol in amniotic fluid in complicated pregnancies. Amer. J. Obstet. Gynecol., in press.

8. Chevalier, G., and Collet, A. J.: In vivo incorporation of choline- ${ }^{3} \mathrm{H}$, Leucine${ }^{3} \mathrm{H}$ and galactose- ${ }^{3} \mathrm{H}$ in alveolar type II pneumocytes in relation to surfactan synthesis. Anat. Rec., 174: 289 (1972).

9. Darrah, H. K., and Hedley-Whyte, J.: Rapid incorporation of palmitate into lung: Site and metabolic fate. J. Appl. Physiol., 34: 205 (1973).

10. Fujiwara, T.: Biochemical aspects of pulmonary alveolar surface lining layer Acta Pathol. Jap., 23: 805 (1972).

11. Gassenheimer, L., Rhoades, R. A., and Scholz, R. W.: In vivo incorporation of ${ }^{14} \mathrm{C}$-1-palmitate and ${ }^{3} \mathrm{H}$-U-glucose into lung lecithin. Resp. Physiol., 15: $268(1972)$.

12. Gentry, M. K., and Olsson, R. A.: A simple, specific radioisotopic assay for 5'-nucleotidase. Anal. Biochem., 64: 624 (1975).

13. Gil, J., and Reiss, O. K.: Isolation and characterization of lamellar bodies and tubular myelin from rat lung homogenates. J. Cell Biol., 58: 152 (1973).

14. Gluck, L., Kulovich, M. V., Borer, R. C., and Keidel, W. N.: The interpretation and significance of the lecithin/sphingomyelin ratio in amniotic fluid. Amer. J. Obstet. Gynecol., 120: 142 (1974).

15. Gluck, L., Motoyama, E. K., Smits, H. L., and Kulovich, M. V.: The biochemical development of surface activity in mammalian lung. Pediat. Res., 1: 237 (1967)

16. Gluck, L., Sribney, M., and Kulovich, M. V.: The biochemical development of surface activity in mammalian lung. Pediat. Res., 1: 247 (1967).

17. Hallman, M., and Gluck, L.: Phosphatidylglycerol in lung surfactant. II Subcellular distribution and mechanism of biosynthesis in vitro. Biochim. Biophys. Acta, 409: 172 (1975)

18. Jobe, A.: Lecithin appearance and biological half-life in rabbit lung. Biochim Biophys. Acta, 489: 440 (1977).

19. Lapetina, E. G., Amaiz, G. R., and DeRobertis, E.: Turnover rates for glycerol, acetate and orthophosphate in phospholipids of the rat cerebral cortex. Biochim. Biophys. Acta, 176: 643 (1969).

20. Mason, R. J.: Lipid metabolism. In: R. G. Crystal: The Biochemical Basis of Pulmonary Function, p. 127 (Marcel Dekker, New York, 1976).

21. Naimark, A.: Cellular dynamics and lipid metabolism in the lung. Fed. Proc. 32: 1968 (1973)

22. Omura, T., Siekevitz, R., and Palade, G. E.: Turnover of constituents of the endoplasmic reticulum membranes of rat hepatocytes. J. Biol. Chem., 242 2389 (1967)

23. Rooney, S. A., Page-Roberts, B. A., and Motoyama, E. K.: Role of lamellar inclusions in surfactant production: Studies on phospholipid composition and biosynthesis in rat and rabbit lung subcellular fractions. J. Lipid Res. and biosynthesis 418 (1975).

24. Rosenthal, M. D., and Geyer, R. P.: Phospholipids acyl group stability in cultured fibroblasts. Biochim. Biophys. Acta, 441: 465 (1976).

25. Soodsma, J. F., Mims, L. C., and Harlow, R. D. The analysis of the molecular species of fetal rabbit lung phosphatidylcholine by consecutive chromatographic techniques. Biochim. Biophys. Acta, 424: 159 (1976).

26. Sottocasa, G. L., Kuylenstiema, B., Eruster, L., and Bergstrand, A.: An electron-transport system associated with the outer membrane of liver mitochondria. J. Cell Biol., 32: 415 (1967).

27. Tierney, D. F., Clements, J. A., and Trahan, H. J.: Rates of replacement of lecithins and alveolar instability in rat lung. Amer. J. Physiol., 213: 671 (1967).

28. Toshima, N., Akino, T., and Ohno, K.: Turnover time of lecithin in lung tissue and alveolar wash of rat. Tohoku J. Exp. Med., 108: 265 (1972)

29. Young, S. L., and Tierney, D. F.: Dipalmitoyl lecithin secretion and metabolism by the rat lung. Amer. J. Physiol. 222: 1539 (1972).

30. We would like to thank Dorothy Miller for typing the manuscript.

31. This work has been funded primarily by an Individual Postdoctoral Fellowship 1-F32-HL/HD 05188 and a Young Investigator Pulmonary Research Grant 1-R23-HL18375 to one of us (A.J.), and by NIH grants HD 04380 and SCOR HL-14169, and support from The National Foundation-March of Dimes C-180A.

32. Requests for reprints should be addressed to: Dr. Alan Jobe, Perinatology Laboratory, Bldg. A-17, Harbor General Hospital, 1000 West Carson St., Torrance, CA 90509 (USA).

33. Received for publication January 10, 1977

34. Accepted for publication August 8, 1977. 